\title{
Human evidence for the involvement of insulin-induced gene 1 in the regulation of plasma glucose concentration
}

\author{
S. Krapivner • E. Chernogubova • M. Ericsson • \\ C. Ahlbeck-Glader • A. Hamsten • F. M. van 't Hooft
}

Received: 7 February 2006 / Accepted: 14 August 2006 / Published online: 15 November 2006

(C) Springer-Verlag 2006

\begin{abstract}
Aims/hypothesis Insulin-induced gene 1 (INSIG1) is a protein that blocks proteolytic activation of sterol regulatory element-binding proteins (SREBPs), transcription factors that activate genes regulating cholesterol and fatty acid metabolism and possibly genes involved in glucose homeostasis. In search of genetic regulation of these processes we examined human INSIGI for common polymorphisms and analysed their associations with biochemical parameters related to lipid and glucose metabolism.

Methods Associations between common polymorphisms in INSIG1 and several biochemical parameters were analysed in a group of 618 healthy, 50-year-old men. A replication analysis was performed in a cohort of 472 healthy, middleaged men. The impact of one promoter polymorphism on oral glucose tolerance was analysed in a subset of 181 subjects. Small interfering RNA (siRNA) inhibition was used to test the significance of INSIG1 for gene expression in human Huh7 hepatoma cells.

Results A potentially functional polymorphism, a $\mathrm{C}$ to $\mathrm{T}$ substitution at position -169 , was discovered in a highly conserved section of the promoter. Significant relationships between the $-169 \mathrm{C}>\mathrm{T}$ polymorphism and plasma glucose concentration were found in two cohorts of healthy, middleaged men $(p<0.01$ and $p<0.02$, respectively). The $-169 \mathrm{~T}$ allele was associated with significantly lower post-load plasma glucose concentrations. A significant $(p=0.02)$
\end{abstract}

S. Krapivner $\cdot$ E. Chernogubova $\cdot$ M. Ericsson $\cdot$

C. Ahlbeck-Glader · A. Hamsten · F. M. van 't Hooft $(\square)$

Atherosclerosis Research Unit, King Gustaf V Research Institute,

Karolinska University Hospital,

17176 Stockholm, Sweden

e-mail: Ferdinand.vant.Hooft@ki.se reduction in expression of phosphoenolpyruvate carboxykinase (PCK2) was observed following siRNA inhibition of INSIG1 in human Huh7 hepatoma cells.

Conclusions/interpretation Population studies demonstrate that INSIG1 plays a role in glucose homeostasis. Experiments with siRNA suggest that this action of INSIG1 is related to SREBP-mediated regulation of PCK2.

Keywords Glucose - Insulin · PCK2 · Polymorphism • SREBP. Transcription
Abbreviations
ACLY ATP citrate lyase
ACSS2 acyl-CoA synthetase short-chain family member 2
FASN fatty acid synthase
FBS fetal bovine serum
FDPS farnesyl diphosphate synthase
HMGCR 3-hydroxy-3-methylglutaryl-Coenzyme A reductase
HMGCS1 3-hydroxy-3-methylglutaryl-Coenzyme A synthase 1
HOMA homeostasis model assessment
HOMA- homeostasis model assessment of insulin
IR resistance
HOMA-B homeostasis model assessment of beta cell function
INSIG1 insulin-induced gene 1
INSIG2 insulin-induced gene 2
LDLR low density lipoprotein receptor
NF-Y nuclear factor Y
PCK2 phosphoenolpyruvate carboxykinase
PCSK9 proprotein convertase subtilisin/kexin type 9
siRNA small interfering RNA
SCAP SREBP cleavage activating protein 


$\begin{array}{ll}\text { SNP } & \text { single nucleotide polymorphism } \\ \text { SP1 } & \text { Sp 1 transcription factor } \\ \text { SRE } & \text { sterol regulatory element } \\ \text { SREBP } & \text { sterol regulatory element-binding protein } \\ \text { USF } & \text { upstream transcription factor }\end{array}$

\section{Introduction}

Insulin-induced gene 1 (INSIG1) was originally identified following the isolation of INSIGI mRNA in the early 1990s, the abundance of which increased when hepatoma cells were treated with insulin [1, 2]. However, the mechanism of this induction and the function of INSIG1 remained unclear. Recently, it was reported that Insigl is upregulated in livers of transgenic mice overexpressing active versions of sterol regulatory element-binding protein 1a (SREBP-1a) and SREBP-2 [3]. Subsequent studies demonstrated that INSIG1 binds SREBP cleavage activating protein (SCAP) in the endoplasmic reticulum, leading to the retention of the SCAP-SREBP complex, thereby preventing proteolytic processing of the SREBPs [4]. This retention process can be overcome by overproduction of SCAP $[5,6]$, strongly suggesting that INSIG1 exists in limited amounts. The corollary is that regulation of INSIG1 protein concentration in the endoplasmic reticulum may be an important mechanism for regulation of the SREBP pathway (reviewed, see [7]).

SREBP-target genes have been identified through studies in transgenic and knock-out mice that overexpress or lack single components of the SREBP pathway [8]. In addition, many direct targets have been uncovered through studies of SREBP binding to promoter regions [8]. Almost all SREBPtarget genes identified thus far are involved in cholesterol and fatty acid metabolism. Nevertheless, several recent studies indicate that the genes encoding phosphoenolpyruvate carboxykinase (PCK2) [9-11] and possibly glucokinase [12-14], two key enzymes in gluconeogenesis and glycolysis, are SREBP-target genes. This suggests that the regulatory role of the SREBPs is not restricted to cholesterol and fatty metabolism, but may also extend to glucose homeostasis. Interestingly, the expression of both INSIGI and SREBP-1 are markedly enhanced by insulin $[1,2,15$, 16], again indicating that INSIG1 may have an as yet undefined role in glucose homeostasis. Indeed, transgenic mice producing nuclear SREBP-1c in adipose tissue show features of congenital generalised lipodystrophy and are characterised by insulin resistance and diabetes mellitus [17].

Taken together, several lines of evidence suggest that the SREBP pathway is involved in the regulation not only of lipid metabolism, but also of glucose homeostasis. Unfortunately, this conclusion is largely based on data derived from studies in rodents. This prompted us to search for possible functional polymorphisms in human INSIGI that could be used to analyse the physiological role of INSIG1 in humans.

Here we describe a potentially functional polymorphism in a highly conserved section of the promoter of INSIGI. The minor allele of this polymorphism is associated with reduced plasma glucose concentration and lower post-load plasma glucose concentrations, as analysed in two cohorts of healthy, middle-aged men. Experiments with small interfering RNA (siRNA) inhibition indicate that this effect may be related to SREBP-mediated suppression of the expression of $P C K 2$.

\section{Subjects and methods}

Subjects Samples from 618 healthy men, all 50 years of age, specifically recruited for metabolic and genetic studies $[18,19]$, were investigated in the present study. Men of identical age were intentionally selected to eliminate the confounding effects of age and sex on lipoprotein and glucose metabolism. Replication analysis was done in two groups ( $n=181, n=291)$ of healthy, middle-aged men who had been sampled as control subjects for case-control studies of young survivors of myocardial infarction [20]. All subjects were selected at random from a registry containing all permanent residents in Stockholm County. For all three cohorts a standardised protocol was used for blood collection and anthropometric measurements. The protocols were approved by the Ethics Committee of the Karolinska Hospital, and all subjects gave informed consent to their participation.

Biochemical assays Blood samples for measurement of concentrations of plasma lipids, lipoproteins and glucose were drawn after a 12-h overnight fast. The major plasma lipoproteins were determined by a combination of preparative ultracentrifugation, precipitation of apolipoprotein Bcontaining lipoproteins and lipid analysis [21]. Blood glucose concentrations were measured by a glucose oxidase method. Plasma insulin was determined by ELISA (Dako Diagnostics, Hamburg, Germany). Insulin resistance and beta cell function were calculated as using the homeostasis model assessment (HOMA) of insulin resistance (HOMAIR) (fasting insulin $[\mathrm{mU} / 1] \times$ fasting glucose $[\mathrm{mmol} / 1] / 22.5$ ) or as HOMA of beta cell function (HOMA-B) $(20 \times$ fasting insulin $[\mathrm{mU} / 1] /$ fasting glucose $[\mathrm{mmol} / \mathrm{l}]-3.5)$.

Polymorphism detection Screening for common genetic variants was performed by direct sequencing in both directions (Big Dye Terminator Chemistry; Applied Biosystems, Foster City, CA, USA) using an ABI3100 
capillary sequencer. We included all exons, $>50 \mathrm{bp}$ of flanking introns, approximately $600 \mathrm{bp}$ of the proximal promoter and approximately $900 \mathrm{bp}$ of the $5^{\prime}$ untranslated region. Sections of approximately $750 \mathrm{bp}$ were amplified and purified using a purification kit (QIAquick PCR; Qiagen, Hilden, Germany). These sections were used as templates for sequencing with nested primers. Primer sequences and PCR conditions are available from the authors.

Genotyping The $-237 \mathrm{~T}>\mathrm{C}$ promoter polymorphism, and the $805-362 \mathrm{~A}>\mathrm{G},-337 \mathrm{~T}>\mathrm{G},-324 \mathrm{~T}>\mathrm{C},-319 \mathrm{C}>\mathrm{T}$, $-318 \mathrm{~A}>\mathrm{G}$, and $-212 \mathrm{~T}>\mathrm{C}$ polymorphisms in intron 5 were analysed using the sequencing technique employed for polymorphism detection. The $-425 \mathrm{~A}>\mathrm{G}$ polymorphism was genotyped $\left(1.25 \mathrm{mmol} / \mathrm{l} \mathrm{MgCl}_{2}, \mathrm{~T}_{\mathrm{ANNEAL}} 59^{\circ} \mathrm{C}\right.$, and $4 \%$ dimethyl sulfoxide) using the forward primer $5^{\prime}$ CGGCTACTGAGAGCACAGC-3' and the reverse primer 5'-CAGGACAGGGTGGGGTTG-3' followed by restriction digestion with BanI. The $537+45 \mathrm{C}>\mathrm{T}$ polymorphism in intron 4 was genotyped $\left(1.5 \mathrm{mmol} / 1 \mathrm{MgCl}_{2}, \mathrm{~T}_{\mathrm{ANNEAL}} 59^{\circ} \mathrm{C}\right.$, without dimethyl sulfoxide) using the forward primer $5^{\prime}$ CAGGGAGATTTCAGGTGATCTT-3' and the reverse primer 5'-TGGATAGCAGCATTTTTGAGAA-3' followed by restriction digestion with Tsp509I. The $805-119 \mathrm{C}>\mathrm{A}$ polymorphism in intron 5 was genotyped $\left(1.5 \mathrm{mmol} / 1 \mathrm{MgCl}_{2}\right.$, $\mathrm{T}_{\text {ANNEAL }} 59^{\circ} \mathrm{C}$, without dimethyl sulfoxide) using the forward primer 5'-TTTTGCAGGTGAGAGCTGTG-3' and the reverse primer 5'-TCATCATTCTCCACCTCCCTA-3' followed by digestion with the restriction enzyme Ss $p$ I. The $-633 \mathrm{G}>\mathrm{C}$ and $-169 \mathrm{C}>\mathrm{T}$ polymorphisms in the promoter were assayed using the Taqman assay-by-design method (Applied Biosystems).

siRNA probes siRNA oligonucleotides specific for INSIGI were designed using siRNA Target Finder (http://www. Ambion.com). siRNAs containing no less than three mismatches with all other known human genes were selected using the BLAST option in Target Finder. siRNA oligonucleotides were synthesised and annealed by a commercial supplier (Sigma-Proligo, The WoodLands, TX, USA). All annealed siRNAs showed a single band when visualised by UV shadowing following PAGE analysis. Two siRNA probes with the most efficient inhibition properties were used throughout this study. The forward sequences of the INSIGI siRNA probes 1 and 2 were 5'-UUACCAACCCGCAGUUUUGTT-3' and 5'CCACCGAUUCUGAGAGCAATT-3, corresponding to the sequences 1326-1347 and 992-1013 of INSIGI mRNA, respectively. A previously described siRNA probe [22] with the forward sequence 5'-CGUACGCGGAAUA CUUCGATT-3, targeting the pGL2 plasmid vector, was used as negative control.
Transfection procedures Human hepatoma Huh7 cells were cultured in DMEM medium (Invitrogen, Carlsbad, CA, USA) supplemented with $10 \%$ fetal bovine serum (FBS), $50 \mathrm{U} / \mathrm{ml}$ penicillin and $50 \mu \mathrm{g} / \mathrm{ml}$ streptomycin. Subconfluent Huh7 cells were preincubated with FBS-free medium for $30 \mathrm{~min}$. The cells were subsequently transfected with $50 \mathrm{nmol} / 1$ gene-specific siRNA or with negative control siRNA using lipofectamin 2000 (Invitrogen) as transfection agent. The transfection medium was removed after $5 \mathrm{~h}$ incubation and the cells were cultured in FBS-free medium for another $24 \mathrm{~h}$.

Real-time quantitative PCR Total cellular RNA was isolated using a kit (RNeasy mini; Qiagen). RNA was quantified spectrophotometrically and the RNA concentrations of all samples were adjusted to $0.1 \mu \mathrm{g} / \mu \mathrm{l}$. Total cDNA was synthesised from $0.5 \mu \mathrm{g}$ RNA in a polymerase reaction using oligoT primer $(2.5 \mathrm{pmol} / \mu \mathrm{l}$ final concentration), dNTPs $(0.5 \mathrm{mmol} / \mathrm{l}$ final concentration) and SuperScript II RNAse $\mathrm{H}^{-}$reverse transcriptase (Invitrogen, Sweden). cDNA from triplicate experiments were pooled and the specific gene expression was analysed by real-time quantitative PCR. All assays and reagents were obtained from Applied Biosystems. Single gene assays were performed using the ABI Prism 7700 sequence detection system (Applied Biosystems) and the Delta Rn analysis method [23]. Multiple gene assays were conducted with the Low Density Array method using the 7900HT Fast Real Time PCR system (Applied Biosystems). Human 18S was used as invariant control. The relative difference in expression was calculated using the $\mathrm{C}_{\mathrm{T}}$ method [24].

Statistical methods Logarithmic transformation was performed on the skewed variables (insulin and triglyceride concentrations, HOMA-B and HOMA-IR) to obtain a normal distribution before statistical computations and significance testing were performed. Differences in continuous variables according to INSIG1 genotype were tested by Student's $t$ test (CC vs $\mathrm{CT}+\mathrm{TT})$. The ConSite program was used for human-mouse sequence comparison, and is available at: http://mordor.cgb.ki.se/cgi-bin/CONSITE/consite/.

\section{Results}

The promoter, exons and intron-exon borders (in total covering nearly $5 \mathrm{~kb}$ ) of INSIGI were screened for common polymorphisms using DNA samples from 18 healthy subjects. No polymorphisms were discovered in the exons or sections close to the intron-exon border. In total, ten single nucleotide polymorphisms (SNPs) were found in the introns: $+58 \mathrm{G}>\mathrm{A}$ and $-295 \mathrm{~T}>\mathrm{C}$ (rs9690097) 
Fig. 1 Human INSIGI gene structure and delineation of the SNPs. The nomenclature for the SNPs in the promoter of the gene is based on the transcription start-site described by Peng et al. [25], while the intronic SNPs are designated on the basis of the mRNA sequence reported by Yang et al. [4]. Exons of INSIGI are shown in boxes



in intron $3,+45 \mathrm{C}>\mathrm{T}(\mathrm{rs} 9718441)$ in intron 4 , and $-362 \mathrm{~A}>\mathrm{G}$ $(\mathrm{rs} 12535901), \quad-337 \mathrm{~T}>\mathrm{G} \quad(\mathrm{rs} 9770059), \quad-324 \mathrm{~T}>\mathrm{C}$ $(\mathrm{rs} 9770060),-319 \mathrm{C}>\mathrm{T},-318 \mathrm{~A}>\mathrm{G}(\mathrm{rs} 9769826),-212 \mathrm{~T}>\mathrm{C}$ (rs9770068), $-119 \mathrm{C}>\mathrm{A}$ (rs9769506) in intron 5 (Fig. 1). Complete agreement was found with the sequence for INSIG1 as presented on the NCBI Homepage, based on the analysis in AC144652. In contrast, a section of the proximal promoter (ranging from -312 to -157 in our analysis) was deleted from the promoter analysis reported by Peng and co-workers [25]. Two SNPs (designated $-169 \mathrm{C}>\mathrm{T}$ and $-237 \mathrm{~T}>\mathrm{C}$ ) were discovered in this section, while two additional SNPs $(-425 \mathrm{~A}>\mathrm{G}$ and $-633 \mathrm{G}>\mathrm{C})$ were found in the more distal section of the promoter.

Pair-wise linkage disequilibrium coefficients $\left(D^{\prime}\right.$ and $\left.r^{2}\right)$ for 12 SNPs were analysed in the first 80 (consecutive) subjects from the cohort of healthy, 50-year old men. Significant linkage disequilibrium was found for all SNPs (Table 1). Complete allelic association was observed between the $-237 \mathrm{~T}>\mathrm{C}$ and $-633 \mathrm{G}>\mathrm{C}$ promoter SNPs.

Potential functional sections of the promoter of INSIG1 and putative binding sites for nuclear factors were evaluated using ConSite [26] for human-mouse sequence compari- son. As shown in Fig. 2a, considerable conservation was observed for the first 600 base pairs of the promoter, with very high conservation for a section surrounding the $-169 \mathrm{C}>\mathrm{T}$ polymorphism. Human-mouse alignment of the promoter sequence with on average $81 \%$ conservation ( -203 to -55 , underlined in Fig. $2 \mathrm{a})$ is shown in Fig. $2 \mathrm{~b}$. Noteworthy is the position of the $-169 \mathrm{C}>\mathrm{T}$ polymorphism, located at the border of a putative nuclear factor-Y (NF-Y) binding site, in the vicinity of putative upstream transcription factor (USF) and Sp 1 transcription factor (SP1) binding sites.

The potential association between four polymorphisms (three promoter SNPs, $-633 \mathrm{G}>\mathrm{C},-425 \mathrm{~A}>\mathrm{G},-169 \mathrm{C}>\mathrm{T}$, and the 805-119C $>\mathrm{A}$ polymorphism in intron 5) and several biochemical parameters related to lipid and glucose metabolism was analysed in a group of 618 healthy, 50year-old men. The frequencies of the minor alleles were $42.9 \%, 31.4 \%, 4.6 \%$ and $44.1 \%$ for the $-633 \mathrm{G}>\mathrm{C}$, $-425 \mathrm{~A}>\mathrm{G},-169 \mathrm{C}>\mathrm{T}$ and the $805-119 \mathrm{C}>\mathrm{A}$ polymorphisms, respectively. All SNPs were in Hardy-Weinberg equilibrium. A significant relationship was observed between the $-169 \mathrm{C}>\mathrm{T}$ polymorphism and the fasting glucose

Table 1 Pair-wise $\left|D^{\prime}\right|$ and $r^{2}$ between SNPs in the INSIG1 gene

\begin{tabular}{|c|c|c|c|c|c|c|c|c|c|c|c|c|}
\hline & $-633 \mathrm{G} / \mathrm{C}$ & $-425 \mathrm{~A} / \mathrm{G}$ & $-237 \mathrm{~T} / \mathrm{C}$ & $-169 \mathrm{C} / \mathrm{T}$ & $+45 \mathrm{C} / \mathrm{T}$ & $-362 \mathrm{~A} / \mathrm{G}$ & $-337 \mathrm{~T} / \mathrm{G}$ & $-324 \mathrm{~T} / \mathrm{C}$ & $-319 \mathrm{C} / \mathrm{T}$ & $-318 \mathrm{~A} / \mathrm{G}$ & $-212 \mathrm{~T} / \mathrm{C}$ & $-119 \mathrm{C} / \mathrm{A}$ \\
\hline$-633 \mathrm{G} / \mathrm{C}(42.9 \%)$ & & 0.57 & 1.00 & 0.06 & 0.28 & 0.20 & 0.86 & 0.86 & 0.27 & 0.83 & 0.83 & 0.97 \\
\hline$-425 \mathrm{~A} / \mathrm{G}(31.4 \%)$ & 0.88 & & 0.57 & 0.07 & 0.13 & 0.29 & 0.39 & 0.39 & 0.08 & 0.43 & 0.38 & 0.45 \\
\hline$-237 \mathrm{~T} / \mathrm{C}(42.9 \%)$ & 1.00 & 0.88 & & 0.06 & 0.28 & 0.20 & 0.86 & 0.86 & 0.27 & 0.83 & 0.83 & 0.97 \\
\hline$-169 \mathrm{C} / \mathrm{T}(4.6 \%)$ & 1.00 & 1.00 & 1.00 & & 0.02 & 0.01 & 0.03 & 0.03 & 0.01 & 0.03 & 0.03 & 0.05 \\
\hline$+45 \mathrm{C} / \mathrm{T}(30.9 \%)$ & 1.00 & 0.76 & 1.00 & 1.00 & & 0.07 & 0.27 & 0.27 & 0.15 & 0.26 & 0.27 & 0.32 \\
\hline$-362 \mathrm{~A} / \mathrm{G}(14.3 \%)$ & 1.00 & 1.00 & 1.00 & 0.98 & 1.00 & & 0.25 & 0.25 & 0.06 & 0.27 & 0.25 & 0.21 \\
\hline$-337 \mathrm{~T} / \mathrm{G}(39.7 \%)$ & 1.00 & 0.67 & 1.00 & 1.00 & 1.00 & 1.00 & & 1.00 & 0.24 & 0.95 & 1.00 & 0.83 \\
\hline$-324 \mathrm{~T} / \mathrm{C}(39.7 \%)$ & 1.00 & 0.67 & 1.00 & 1.00 & 1.00 & 1.00 & 1.00 & & 0.24 & 0.95 & 1.00 & 0.83 \\
\hline$-319 \mathrm{C} / \mathrm{T}(26.3 \%)$ & 1.00 & 0.62 & 1.00 & 1.00 & 1.00 & 1.00 & 1.00 & 1.00 & & 0.22 & 0.24 & 0.28 \\
\hline$-318 \mathrm{~A} / \mathrm{G}(38.5 \%)$ & 1.00 & 0.68 & 1.00 & 1.00 & 1.00 & 0.99 & 1.00 & 1.00 & 1.00 & & 0.95 & 0.79 \\
\hline$-212 \mathrm{~T} / \mathrm{C}(39.7 \%)$ & 0.97 & 0.67 & 0.97 & 1.00 & 1.00 & 1.00 & 1.00 & 1.00 & 1.00 & 1.00 & & 0.81 \\
\hline -119C/A (44.1\%) & 1.00 & 0.79 & 1.00 & 1.00 & 1.00 & 1.00 & 1.00 & 1.00 & 1.00 & 1.00 & 0.97 & \\
\hline
\end{tabular}

Pair-wise linkage disequilibrium coefficients $\left(D^{\prime}\right.$ and $\left.r^{2}\right)$ for the SNPs were evaluated in a subgroup of 80 subjects from the study population using the EMLD program (http://request.mdacc.tmc.edu/ qhuang/Software/pub.htm). The $\left|D^{\prime}\right|$ and $r^{2}$ values are shown in the lower left and upper right sections of the table, respectively. The frequency of the minor allele for each SNP is shown in brackets. 
Fig. 2 Human-mouse sequence comparison and delineation of putative binding sites for nuclear factors. a Graphic presentation of the percentage conservation between the human and mouse sequences, as determined by ConSite (see Methods). Bar at -200 to -55 , most conserved section of the promoter of INSIGI.

b Alignment of the most conserved section of the promoter of INSIGI, as analysed by the BLAST2 program (NCBI, see Methods), and identification of putative binding sites for nuclear factors that are shared by the human and mouse promoter. $N F-Y$, nuclear factor-Y; $U S F$, upstream transcription factor; $S P 1, \mathrm{Sp} 1$ transcription factor

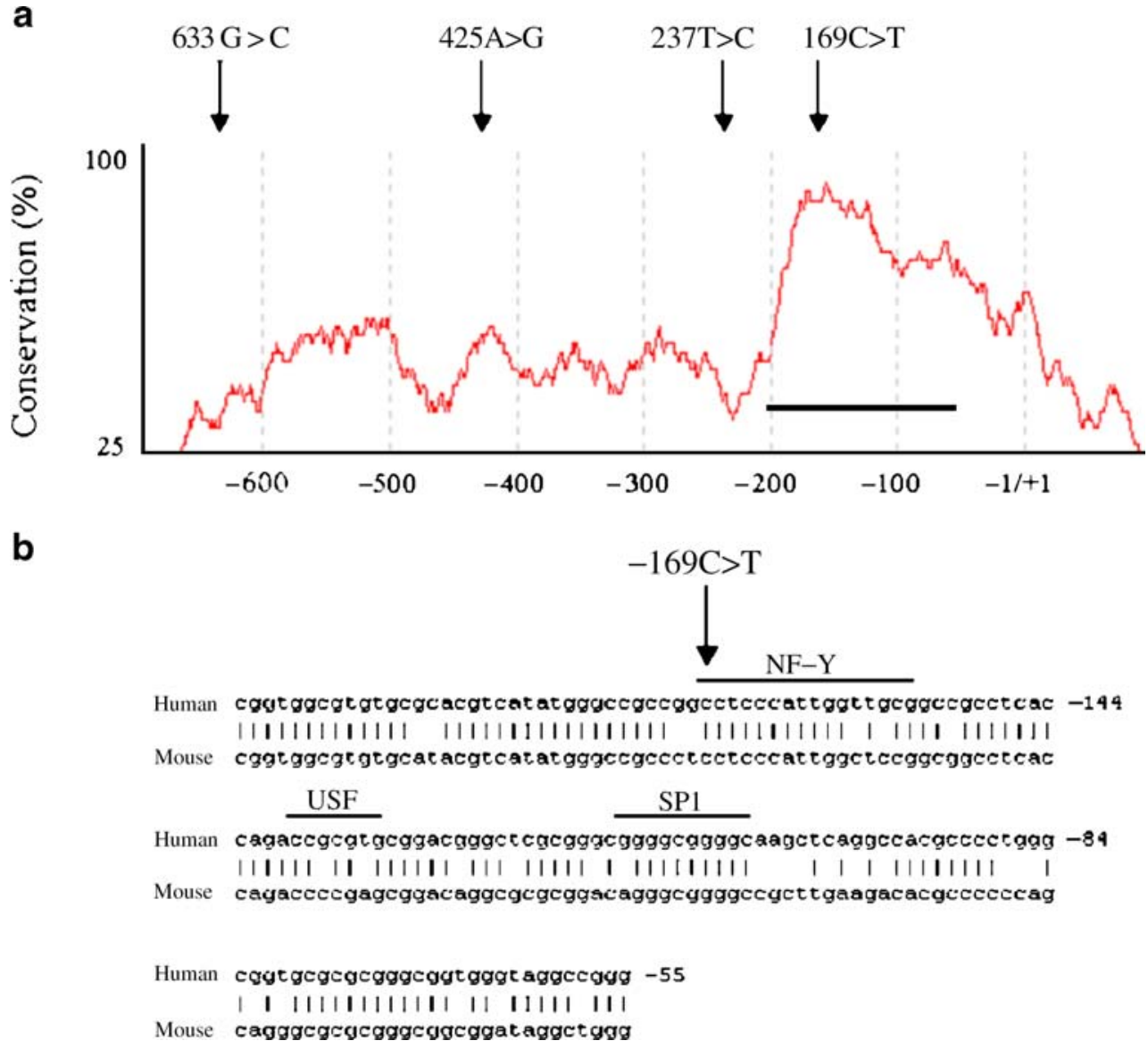

concentration (Table 2), whereas other relevant biochemical and anthropometric measurements showed no relationships with the $-169 \mathrm{C}>\mathrm{T}$ polymorphism. No significant relationships with biochemical and anthropometric parameters were observed for the $-633 \mathrm{G}>\mathrm{C},-425 \mathrm{~A}>\mathrm{G}$ and $805-119 \mathrm{C}>\mathrm{A}$

Table 2 Association of the $-169 \mathrm{C}>\mathrm{T}$ polymorphism with fasting plasma glucose concentration and other biochemical and anthropometric measurements in a cohort of 618 healthy, 50-year-old men

\begin{tabular}{llll}
\hline & \multicolumn{2}{l}{$-169 \mathrm{C} / \mathrm{T}$ polymorphism } & \\
\cline { 2 - 4 } & $\mathrm{C} / \mathrm{C}$ & $\mathrm{C} / \mathrm{T}+\mathrm{T} / \mathrm{T}$ & $p$ \\
\hline$n$ & 561 & 57 & \\
Glucose $(\mathrm{mmol} / \mathrm{l})$ & $4.99 \pm 0.75$ & $4.79 \pm 0.46$ & $<0.01$ \\
Insulin $(\mathrm{pmol} / \mathrm{l})$ & $44 \pm 25$ & $40 \pm 22$ & $\mathrm{NS}$ \\
HOMA-B & $108 \pm 82$ & $118 \pm 83$ & $\mathrm{NS}$ \\
HOMA-IR & $1.67 \pm 1.03$ & $1.42 \pm 0.80$ & $\mathrm{NS}$ \\
Body mass index $\left(\mathrm{kg} / \mathrm{m}^{2}\right)$ & $26.0 \pm 3.3$ & $25.5 \pm 2.6$ & $\mathrm{NS}$ \\
Cholesterol (mmol/l) & $5.38 \pm 0.97$ & $5.38 \pm 1.05$ & $\mathrm{NS}$ \\
LDL-cholesterol $(\mathrm{mmol} / \mathrm{l})$ & $3.58 \pm 0.88$ & $3.57 \pm 0.84$ & $\mathrm{NS}$ \\
HDL-cholesterol, $(\mathrm{mmol} / \mathrm{l})$ & $1.23 \pm 0.34$ & $1.21 \pm 0.31$ & $\mathrm{NS}$ \\
Triacylglycerol $(\mathrm{mmol} / \mathrm{l})$ & $1.56 \pm 0.97$ & $1.58 \pm 0.93$ & $\mathrm{NS}$ \\
\hline
\end{tabular}

Values are mean $\pm \mathrm{SD}$. HOMA-B, homeostasis model assessment of beta cell function; HOMA-IR, homeostasis model assessment of insulin resistance polymorphisms. However, all three polymorphisms showed a borderline significant relationship with the fasting plasma glucose concentration.

A replication analysis was performed in a cohort of 472 healthy, middle-aged men (aged $48.1 \pm 7.7$ years; mean \pm SD). Again, a statistically significant relationship was observed between the $-169 \mathrm{C}>\mathrm{T}$ polymorphism and the fasting plasma glucose concentration $(p<0.02)$, while no relationships with other biochemical and anthropometric measurements were found (Table 3).

The potential impact of the $-169 \mathrm{C}>\mathrm{T}$ polymorphism on oral glucose tolerance was analysed in one of the cohorts $(n=181)$ from the replication study. As shown in Fig. 3, significantly lower plasma glucose levels were found at time points 30,45 and $60 \mathrm{~min}$ in subjects carrying the $-169 \mathrm{~T}$ allele than in subjects homozygous for the $-169 \mathrm{C}$ allele. Overall, the population studies indicate that the $-169 \mathrm{~T}$ allele is associated with a significant reduction in fasting glucose concentration and enhanced clearance of glucose compared with the $-169 \mathrm{C}$ allele.

The mechanism of action by which INSIG1 influences glucose homeostasis was analysed in human Huh7 hepatoma cells using siRNA inhibition of INSIG1. As expected, siRNA inhibition was associated with a marked reduction in INSIG1 mRNA concentration (Table 4). No reciprocal 
Table 3 Association of $-169 \mathrm{C}>\mathrm{T}$ polymorphism with fasting plasma glucose concentration and other biochemical and anthropometric measurements in a cohort of 472 healthy, middle-aged men

\begin{tabular}{llll}
\hline & \multicolumn{2}{l}{$-169 \mathrm{C} / \mathrm{T}$ polymorphism } \\
\cline { 2 - 4 } & $\mathrm{C} / \mathrm{C}$ & $\mathrm{C} / \mathrm{T}+\mathrm{T} / \mathrm{T}$ & $p$ \\
\hline$n$ & 428 & 44 & \\
Age (years) & $48.0 \pm 7.6$ & $48.2 \pm 7.7$ & $\mathrm{NS}$ \\
Glucose (mmol/l) & $5.18 \pm 0.90$ & $4.83 \pm 0.74$ & 0.02 \\
Insulin (pmol/1) & $48 \pm 26$ & $48 \pm 24$ & $\mathrm{NS}$ \\
HOMA-B & $95 \pm 74$ & $100 \pm 61$ & $\mathrm{NS}$ \\
HOMA-IR & $1.97 \pm 1.49$ & $1.90 \pm 1.02$ & $\mathrm{NS}$ \\
BMI $\left(\mathrm{kg} / \mathrm{m}^{2}\right)$ & $25.9 \pm 3.6$ & $25.2 \pm 2.5$ & $\mathrm{NS}$ \\
Cholesterol $(\mathrm{mmol} / \mathrm{l})$ & $5.44 \pm 0.98$ & $5.46 \pm 0.98$ & $\mathrm{NS}$ \\
Triacylglycerol $(\mathrm{mmol} / \mathrm{l})$ & $1.41 \pm 0.77$ & $1.44 \pm 0.77$ & $\mathrm{NS}$ \\
\hline
\end{tabular}

Values are mean $\pm \mathrm{SD}$. HOMA-B, homeostasis model assessment of beta cell function; HOMA-IR, homeostasis model assessment of insulin resistance

increase in INSIG2 mRNA concentration was noted. Moreover, no effect of the control pGL2 siRNA probe on gene expression was observed. Comparable effects were observed when two different siRNA probes for the inhibition of INSIG1 were used (not shown). The impact of INSIGI siRNA inhibition on the expression of more than 40 different genes, primarily related to cholesterol, fatty acid and lipoprotein metabolism, was analysed. As expected, all eight known SREBP-target genes evaluated in this study (ACSS2, FASN, HMGCR, and PCSK9 [Table 4], and ACLY, FDPS, HMGCS1 and LDLR [not shown], see Abbreviations list) showed a more than 1.5fold increase in expression. None of the genes related to lipoprotein metabolism exhibited a change in expression

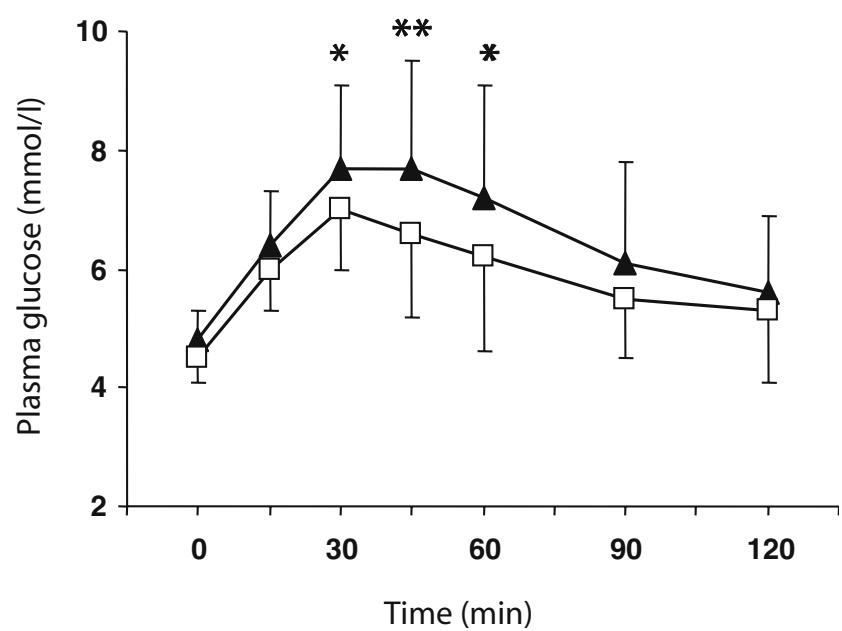

Fig. 3 Impact of $-169 \mathrm{C}>\mathrm{T}$ polymorphism on oral glucose tolerance. Plasma glucose concentrations were analysed according to INSIGI $-169 \mathrm{C}>\mathrm{T}$ genotype. Subjects heterozygous or homozygous for the $-169 \mathrm{~T}$ allele $(n=18)$ (open squares) had faster glucose clearance than subjects homozygous for the $-169 \mathrm{C}$ allele $(n=163)$ (filled triangles). ${ }^{*} p<0.05,{ }^{* *} p<0.01$ following siRNA inhibition of INSIG1. In addition, the expression of two genes with critical roles in glucose homeostasis, glucokinase and PCK2, was analysed. The glucokinase mRNA concentrations were extremely low in the Huh7 cells and it was not possible to evaluate changes in expression of this gene. However, a significant reduction in the expression of $P C K 2$ following siRNA inhibition of INSIG1 was observed (Table 4).

\section{Discussion}

This study reports the discovery of a potentially functional polymorphism in a highly conserved section of the promoter of INSIG1. Significant relationships between the $-169 \mathrm{C}>\mathrm{T}$ polymorphism and plasma glucose concentration were found in two cohorts of healthy, middle-aged men. Moreover, the $-169 \mathrm{~T}$ allele was associated with significantly lower post-load plasma glucose concentrations. These observations suggest that the polymorphism influences the transcription of $I N S I G I$, thereby regulating the concentration of the INSIG1 protein, ultimately leading to changes in plasma glucose metabolism.

The pioneering work of Brown and Goldstein has highlighted the role of INSIG1 in the SREBP pathway, and consequently in the regulation of cholesterol and fatty acid metabolism (review, see [7]). Nevertheless, several recent studies indicate that INSIG1 may have additional functions. First, DeBose-Boyd and co-workers have reported that INSIG1 is directly involved in the ubiquitination and degradation of 3-hydroxy-3-methylglutaryl-CoA reductase $[27,28]$, a process that is independent of INSIG1-SCAP interaction and activation of the SREBP pathway. Second, Unger and co-workers have provided evidence for a role of INSIG1 in diet-induced obesity [29] and demonstrated that Insig1 expression restricts lipogenesis in mature adipocytes and blocks differentiation in preadipocytes [30]. The present study provides another example of the multifunctional role of INSIG1, and

Table 4 Effect of siRNA inhibition of INSIGI on gene expression in human Huh7 hepatoma cells

\begin{tabular}{lll}
\hline Gene & Fold change & $p$ \\
\hline INSIG1 & $0.23 \pm 0.04$ & $<0.001$ \\
INSIG2 & $1.16 \pm 0.27$ & $\mathrm{NS}$ \\
Acetyl-CoA synthetase & $1.89 \pm 0.33$ & 0.04 \\
Fatty acid synthase & $2.15 \pm 1.05$ & $\mathrm{NS}$ \\
HMG-CoA reductase & $1.90 \pm 1.07$ & $\mathrm{NS}$ \\
PCSK9 & $2.35 \pm 1.61$ & $\mathrm{NS}$ \\
PCK2 & $0.40 \pm 0.09$ & 0.02 \\
\hline
\end{tabular}

Values are mean $\pm \mathrm{SD}$ of three experiments. 
presents evidence that INSIG1 is implicated in the regulation of the plasma glucose concentration in humans.

A significant relationship between the fasting glucose concentration and the $-169 \mathrm{C}>\mathrm{T}$ polymorphism was found in the population studies, while only borderline significant relationships were observed between the fasting glucose concentration and the other polymorphisms in the INSIGI promoter. This indicates that the $-169 \mathrm{C}>\mathrm{T}$ polymorphism is of functional significance. We performed additional sequencing analysis of the region of INSIGI used for screening of common genetic variants (see polymorphism detection in Subjects and methods) in eight subjects heterozygous for the $-169 \mathrm{C}>\mathrm{T}$ polymorphism in order to rule out the possibility that a rare polymorphism in linkage disequilibrium with the $-169 \mathrm{C}>\mathrm{T}$ polymorphism was responsible for this relationship, but no additional polymorphisms were found. Another indication that the $-169 \mathrm{C}>\mathrm{T}$ polymorphism may be of functional significance is the location of the polymorphism in a highly preserved region of the INSIG1 promoter, suggesting that this section is of importance for the regulation of expression of INSIGI. Putative binding sites for the transcription factors NF-Y, USF and SP1 were uncovered in this section with the aid of a computer program designed to find binding sites for nuclear factors that are shared by human and mouse promoters. The $-169 \mathrm{C}>\mathrm{T}$ polymorphism is on the edge of the NF-Y binding site, upstream from the ATTGG sequence critical for binding of NF-Y [31]. It is thus conceivable that the $-169 \mathrm{C}>\mathrm{T}$ polymorphism alters the binding affinity of NF-Y, ultimately leading to a change in the rate of transcription of INSIGI.

Interestingly, INSIG1 is a direct SREBP target gene [8] and sterol regulatory element (SRE)-containing promoters absolutely require NF-Y or SP1 as cofactors for SREBP activation [31-33]. It is therefore intriguing that the clustering of putative binding sites for NF-Y, SP1 and USF was found in a highly conserved section of the human and mouse INSIG1 promoter. It is tempting to speculate that these binding sites mediate transcriptional regulation by the SREBPs. However, the proposed USF binding site is not highly homologous to established SREs or E-boxes. Moreover, an SRE was recently described [34] in the human INSIG1 promoter (located between -545 and -536 , see Fig. 2a), but an equivalent SRE sequence does not seem to be conserved in the mouse Insig1 promoter. In all, additional in vitro studies will be required to evaluate in detail the transcriptional regulation of INSIGI and to establish the role of the $-169 \mathrm{C}>\mathrm{T}$ polymorphism in this process.

The association studies presented in this report indicate that INSIG1 is involved in the regulation of glucose metabolism, presumably as a consequence of the role of INSIG1 in SREBP-regulated transcription. It is noteworthy that a combined analysis of gene expression data from livers of transgenic and knockout mice did not identify genes involved in either glycolysis or gluconeogenesis as direct SREBP target genes [8]. Nevertheless, other lines of evidence indicate that the SREBPs are involved in the transcriptional regulation of $P C K 2$ [9-11] and possibly glucokinase [12-14]. We therefore employed siRNA inhibition to explore the possible role of INSIG1 in regulating expression of these genes in the human hepatoma Huh7 cell-line. All SREBP-target genes analysed in this study showed a more than 1.5 -fold increase in expression following INSIGI siRNA inhibition. In addition, a significant reduction in the expression of $P C K 2$ following knockdown of INSIGI was observed. This observation is in line with another study [11], which demonstrated that overproduction of SREBPs inhibited the transcription of $P C K 2$. On the basis of these studies it is proposed that the $-169 \mathrm{~T}$ allele has a lower rate of transcription of INSIGI than the $-169 \mathrm{C}$ allele, leading to reduced INSIG1 concentrations in the endoplasmic reticulum. This in turn influences the transfer of SREBPs from the endoplasmic reticulum to the Golgi, leading to a reduced expression of the SREBP target gene PCK2. As a consequence, subjects with the $-169 \mathrm{~T}$ allele exhibit reduced fasting glucose concentrations and enhanced clearance of glucose as compared with individuals with the $-169 \mathrm{C}$ allele. It must be stressed that although several components of this hypothesis have not been tested experimentally, this working model is compatible with all the data presented in this report.

There are several alternative explanations for the observed relationship between the $-169 \mathrm{C}>\mathrm{T}$ polymorphism in INSIGI and glucose homeostasis. It is, for example, possible that the expression of other hepatic genes involved in gluconeogenesis or glycolysis mediate this effect. In addition, it cannot be excluded that a hepatic gene with an as yet unknown mechanism of action upon glucose homeostasis is the cause of this phenomenon. For example, we found (E. Chernogubova, unpublished observation) that siRNA inhibition of INSIG1 was associated with a marked increase in expression of lipin 1 gene, a lipodystrophy and obesity gene [35] recently implicated in human glucose metabolism [36]. Finally, while INSIG1 is expressed in all human tissues analysed thus far (S. Krapivner, unpublished observation), it is possible that INSIG1-dependent changes in the activation of the SREBP pathway in extra-hepatic cells involved in the regulation of glucose metabolism, e.g. adipose, skeletal muscle and pancreatic beta cells, may influence glucose homeostasis. Thus, in agreement with other studies $[29,30]$, it is feasible that the effect of INSIG1 on adipocyte metabolism is the primary cause of the observed relationship between the $-169 \mathrm{C}>\mathrm{T}$ polymorphism in INSIGI and glucose homeostasis. In short, more detailed analysis of the role of INSIG1 in the metabolism of hepatic and extra-hepatic tissues will be required to 
resolve the mechanism of action of INSIG1 in glucose homeostasis.

Recent studies in rodents indicate that INSIG1 and -2 have complementary roles in the regulation of the SREBP pathway [7]. In these studies it was found that Insig I knock-out mice did not exhibit detectable phenotypic changes, and only a combined knock-out of Insigl and Insig2 showed the expected effects on SREBP-target genes [37]. If the same conditions apply to the human situation, it is difficult to envisage that a change in the transcription of INSIG1 alone could lead to changes in glucose homeostasis. However, under various experimental conditions we have consistently observed significant effects of siRNA inhibition of INSIGI on the expression of SREBP-target genes in human hepatoma cells (E. Chernogubova, unpublished observation). Moreover, no complementary increase in INSIG2 mRNA was observed. These observations suggest that INSIG1 plays a more prominent role in human liver cells than in hepatic metabolism in rodents.

Acknowledgements This study was supported by grants from the Swedish Medical Research Council, the Swedish Heart-Lung Foundation, the Torsten and Ragner Söderberg Foundation, the Petrus and Augusta Hedlund Foundation, the King Gustaf V 80th Birthday Foundation, the Foundation for Old Servants, the Fredrik and Ingrid Thuring Foundation, and the Stockholm County Council.

\section{References}

1. Mohn KL, Laz TM, Hsu JC, Melby AE, Bravo R, Taub R (1991) The immediate-early growth response in regenerating liver and insulin-stimulated H-35 cells: comparison with serum-stimulated $3 \mathrm{~T} 3$ cells and identification of 41 novel immediate-early genes. Mol Cell Biol 11:381-390

2. Diamond RH, Du K, Lee VM et al (1993) Novel delayed-early and highly insulin-induced growth response genes: identification of HRS, a potential regulator of alternative pre-mRNA splicing. J Biol Chem 268:15185-15192

3. Luong A (2000) Identification of three novel SREBP-activated target genes: acetyl CoA synthetase, 3 - $\beta$-hydroxysterol dehydrogenase, and CL-6/INSIG1. PhD thesis, Southwestern Medical Center, University of Texas at Dallas, pp 1-137

4. Yang T, Espenshade PJ, Wright ME et al (2002) Crucial step in cholesterol homeostasis: sterols promote binding of SCAP to INSIG-1, a membrane protein that facilitates retention of SREBPs in ER. Cell 110:489-500

5. Hua X, Norturfft A, Goldstein JL, Brown MS (1996) Sterol resistance in $\mathrm{CHO}$ cells traced to point mutation in SREBP cleavage activating protein. Cell 87:415-426

6. Yang T, Goldstein JL, Brown MS (2000) Overexpression of membrane domain of SCAP prevents sterols from inhibiting SCAP. SREBP exit from endoplasmic reticulum. J Biol Chem 275:29881-29886

7. Goldstein JL, DeBose-Boyd RA, Brown MS (2006) Protein sensors for membrane sterols. Cell 124:35-46

8. Horton JD, Shah NA, Warrington JA et al (2003) Combined analysis of oligonucleotide microarray data from transgenic and knockout mice identifies direct SREBP target genes. Proc Natl Acad Sci USA 100:12027-12032

9. Chakravarty K, Leahy P, Becard D et al (2001) Sterol regulatory element-binding protein-1c mimics the negative effect of insulin on phosphoenolpyruvate carboxykinase (GTP) gene transcription. J Biol Chem 276:34816-34823

10. Becard D, Hainault I, Azzout-Marniche D et al (2001) Adenovirus-mediated overexpression of sterol regulatory element binding protein-1c mimics insulin effects on hepatic gene expression and glucose homeostasis in diabetic mice. Diabetes 50 : 2425-2430

11. Chakravarty K, Wu SY, Chiang CM, Samols D (2004) SREBP-1c and $\mathrm{Sp} 1$ interact to regulate transcription of the gene for phosphoenolpyruvate carboxykinase (GTP) in the liver. J Biol Chem 279:15385-15395

12. Foretz M, Guichard C, Ferre P, Foufelle F (1999) Sterol regulatory element binding protein-1c is a major mediator of insulin action on the hepatic expression of glucokinase and lipogenesis-related genes. Proc Natl Acad Sci USA 96:12737-12742

13. Kim SY, Kim HI, Kim TH et al (2004) SREBP-1c mediates the insulin-dependent hepatic glucokinase expression. J Biol Chem 279:30823-30829

14. Gregori C, Guillet-Deniau I, Girard J, Decaux JF, Pichard AL (2005) Insulin regulation of glucokinase gene expression: evidence against a role for sterol regulatory element binding protein 1 in primary hepatocytes. FEBS Lett 580:410-414

15. Foretz M, Pacot C, Dugail I et al (1999) ADD1/SREBP-1c is required in the activation of hepatic lipogenic gene expression by glucose. Mol Cell Biol 19:3760-3768

16. Shimomura I, Bashmakov Y, Ikemoto S et al (1999) Insulin selectively increases SREBP-1c mRNA in the livers of rats with streptozotocin-induced diabetes. Proc Natl Acad Sci USA 96: 13656-13661

17. Shimomura I, Hammer RE, Richardson JA et al (2003) Insulin resistance and diabetes mellitus in transgenic mice expressing nuclear SREBP-1c in adipose tissue: model for congenital generalized lipodystrophy. Genes Dev 12:3182-3194

18. Van 't Hooft FM, Ruotolo G, Boquist S, de Faire U, Eggertsen G, Hamsten A (2001) Human evidence that the apolipoprotein A-II gene is implicated in visceral fat accumulation and metabolism of triglyceride-rich lipoproteins. Circulation 104:1223-1228

19. Gertow K, Skoglund-Andersson C, Eriksson P et al (2003) A common polymorphism in the fatty acid transport protein-1 gene associated with elevated post-prandial lipaemia and alterations in LDL particle size distribution. Atherosclerosis 167:265-273

20. Moor E, Silveira A, van 't Hooft FM et al (1995) Coagulation factor VII mass and activity in young men with myocardial infarction at a young age. Role of plasma lipoproteins and factor VII genotype. Arterioscler Thromb Vasc Biol 15:655-664

21. Carlson K (1973) Lipoprotein fractionation. J Clin Pathol 26:32-37

22. Elbashir S, Harborth J, Lendeckel W, Yalcin A, Weber K, Tuschl T (2001) Duplexes of 21-nucleotide RNAs mediate RNA interference in cultured mammalian cells. Nature 411:494-498

23. Heid CA, Stevens J, Livak KJ, Williams PM (1996) Real time quantitative PCR. Genome Res 6:986-994

24. Livak KJ, Schmittgen TD (2001) Analysis of relative gene expression data using real time quantitative PCR and the $2^{-\Delta \Delta C t}$ method. Methods 25:402-408

25. Peng Y, Schwarz EJ, Lazar MA, Genin A, Spinner NB, Taub R (1997) Cloning, human chromosomal assignment, and adipose and hepatic expression of the CL-6/INSIG1 gene. Genomics 43:278-284

26. Sandelin A, Wasserman WW, Lenhard B (2004) ConSite: webbased prediction of regulatory elements using cross-species comparison. Nucleic Acids Res 32:W249-W252

27. Sever N, Song BL, Yabe D, Goldstein JL, Brown MS, DeBose-Boyd RA (2003) Insig-dependent ubiquitination and degradation of 
mammalian 3-hydroxy-3-methylglutaryl-CoA reductase stimulated by sterols and geranylgeraniol. J Biol Chem 278:52479-52490

28. Sever N, Yang T, Brown MS, Goldstein JL, DeBose-Boyd RA (2003) Accelerated degradation of HMG CoA reductase mediated by binding of Insig-1 to its sterol-sensing domain. Mol Cell 11: 25-33

29. Li J, Yu X, Pan W, Unger RH (2002) Gene expression profile of rat adipose tissue at the onset of high-fat obesity. Am J Physiol 282: E1334-E1341

30. Li J, Takaishi K, Cook W, McCorkle SK, Unger RH (2003) Insig1 "brakes" lipogenesis in adipocytes and inhibits differentiation of preadipocytes. Proc Natl Acad Sci USA 100:9476-9481

31. Jackson SM, Ericsson J, Osborne TF, Edwards PA (1995) NF-Y has a novel role in sterol-dependent transcription of two cholesterogenic genes. J Biol Chem 270:21445-21448

32. Sanchez HB, Yieh L, Osborne TF (1995) Cooperation by sterol regulatory element-binding protein and $\mathrm{Sp} 1$ in sterol regulation of low density lipoprotein receptor gene. J Biol Chem 270:1161-1169
33. Bennett MK, Osborne TF (2000) Nutrient regulation of gene expression by sterol regulatory element binding proteins: increased recruitment of gene-specific coregulatory factors and selective hyperacetylation of histone H3 in vivo. Proc Natl Acad Sci USA 97:6340-6344

34. Kast-Woelbern HR, Dana SL, Cesario RM et al (2004) Rosiglitazone induction of Insig-1 in white adipose tissue reveals a novel interplay of peroxisome proliferator-activated receptor $\gamma$ and sterol regulatory element-binding protein in the regulation of adipogenesis. J Biol Chem 279:23908-23915

35. Phan J, Reue K (2005) Lipin, a lipodystrophy and obesity gene. Cell Metab 1:73-83

36. Suviolahti E, Reue K, Cantor RM et al (2006) Cross-species analyses implicate Lipin 1 involvement in human glucose metabolism. Hum Mol Genet 15:377-386

37. Engelking LJ, Liang G, Hammer RE et al (2005) Schoenheimer effect explained - feedback regulation of cholesterol synthesis in mice mediated by Insig proteins. J Clin Invest 115:2489-2498 